\title{
Reassesment of Dawndraco kanzai Kellner, 2010 and reassignment of the type specimen to Pteranodon sternbergi Harksen, 1966
}

\author{
Elizabeth Martin-Silverstone, ${ }^{\star, 1,2}$ James R.N. Glasier ${ }^{3}$, John H. Acorn ${ }^{4}$, \\ Sydney Mohr ${ }^{5}$, and Philip J. Currie ${ }^{5}$
}

${ }^{1}$ Ocean and Earth Science, National Oceanography Centre, University of Southampton, European Way, Southampton, UK, SO14 3ZH, E.G.Martin@soton.ac.uk

${ }^{2}$ School of Earth Sciences, Wills Memorial Building, Queens Road, University of Bristol, Bristol, UK, BS8 4RJ. ${ }^{3}$ Evolution and Ecology Research Centre, School of Biological, Earth and Environmental Sciences, University of New South Wales, Sydney, New South Wales 2052 Australia; jglasier@student.unsw.edu.au

${ }^{4}$ Department of Renewable Resources, University of Alberta, Edmonton, Alberta, Canada, T6G 2H1; jacorn@ualberta.ca ${ }^{5}$ Department of Biological Sciences, University of Alberta, Edmonton, Alberta, Canada, T6G 2E9; pjcurrie@ualberta.ca

\begin{abstract}
The previous most comprehensive study on Pteranodon recognized two species: P. longiceps and P. sternbergi, but complete skeletons of Pteranodon are rare. One of the best preserved (UALVP 24238) has been identified as both P. sternbergi and as a new genus and species, Dawndraco kanzai. Here, the specimen is redescribed, additional portions of the rostrum are identified for the first time, new details of the specimen's provenance and preparation history are presented, and its taxonomic placement is discussed. Whereas the shape of the rostrum appears at first glance to distinguish it from known Pteranodon, this feature is more parsimoniously interpreted in the context of sexual dimorphism; a male has a longer and therefore more shallowly tapering rostrum. Metrics from this specimen, and from published photographs and illustrations, support the conclusion that the rostrum of UALVP 24238 is not unique, and so provides no grounds for recognition of a taxon distinct from Pteranodon sternbergi. Other putatively unique features of UALVP 24238 are examined and found unconvincing.
\end{abstract}

\section{INTRODUCTION}

The large flying reptile Pteranodon Marsh, 1876 is known from over 1,100 specimens (Bennett 2001a), most of which were collected from the Smoky Hill Chalk Member (Upper Cretaceous, Coniacian to Campanian) of the Niobrara Formation of Kansas, USA. It is one of the most common pterosaurs known, although most remains are fragmentary (Bennett 1994). First described by Marsh (1871) as 'Pterodactylus oweni', specimens subsequently have been assigned to at least 9 genera and 15 species (Bennett 1994; Kellner 2010). Apparent taxonomic complexity, combined with the large number of specimens available, led to analyses of stratigraphic distribution, anatomy, growth, variation and sexual dimorphism of Pteranodon (Bennett 1992, 1993, 1994, 2001a, 2001b; Bennett and Penkalski

\footnotetext{
*corresponding author

Published April 6, 2017

(c) 2017 by the authors

submitted Dec. 9, 2016; revisions received March 24 2017; ac-

cepted March 29 2017. Handling editor: Robert Holmes.

DOI 10.18435/B5059J
}

in press). First, Bennett (1992) convincingly demonstrated a bimodal pattern for the sizes of a number of postcranial elements, based on sample sizes in the hundreds. The few specimens that are complete enough suggest that large adult body size is associated with a large cranial crest and a small pubic canal (Bennett 1992). Conversely, smaller adult body size is associated with a small cranial crest and a larger pubic canal, strongly suggesting that the bimodal pattern represents sexual dimorphism. Furthermore, specimens with upright crests and those with rearward-leaning crests are stratigraphically separated, suggesting the existence of two species that lived at different times (Bennett 1994). This led to the recognition of only two named Pteranodon species: P. longiceps Marsh, 1876 and P. sternbergi Harksen, 1966. The remaining species became nomina nuda or junior synonyms, the products of typological oversplitting (Bennett 1994). Additional studies of Pteranodon have recognized patterns in ontogenetic variation revealing juvenile, subadult and adult morphs (Bennett 1993), differences in significant anatomical descriptions (Bennett 2001a), functional morphology (Bennett 2001b), and most recently recognition of bone deposition patterns in the rostrum 
(Bennett and Penkalski In Press). These studies have lead to a wider understanding of pterosaur ontogeny (Bennett 1995, 1996), sexual dimorphism (Lü et al. 2011), and myology (Bennett 2003, 2008).

However, not all authors agree with Bennett's classification. Kellner (2010) recognizes only one Pteranodon species, P. longiceps, placing P. sternbergi in Geosternbergia Miller, along with a new species, G. maiseyi (type and sole specimen is KUVP 27821). He also describes a new genus and species, Dawndraco kanzai, with UALVP 24238 as the type and only specimen. No phylogenetic analysis is presented, and these decisions appear to represent a preference for taxonomic splitting. The re-evaluation of Pteranodon sensu lato by Kellner (2010) is troubling for pterosaur palaeontology, as so much of our understanding of pterosaur ontogeny and growth stem from Bennett's work on Pteranodon and the conclusion that Pteranodon specimens can be divided into two closely and perhaps anagenetically related species. Kellner's claim that multiple genera are involved calls into question a number of studies that have been based on the assumption that Bennett's work provides a solid foundation of pterosaur science.

UALVP 24238 (Figs. 1, 2) is an almost complete, well-preserved skeleton, and it is therefore worthy of additional scrutiny. Bennett (1992, 1994, 2001a) previously identified this specimen as a large-morph (male) example of $P$. sternbergi, in part due to its provenience in the lower part of the Smoky Hill Chalk Member. Here, UALVP 24238 is described in detail, and the taxonomic controversy is addressed.

Institutional Abbreviations: $\mathrm{AMNH}$, American Museum of Natural History, New York; CMCVP, Cincinnati Museum Center, Cincinnati; CMNFV, Canadian Museum of Nature, Ottawa, Ontario, Canada; FHSM, Sternberg Museum of Natural History, Fort Hays State University, Fort Hays, Kansas; KUVP, Natural History Museum, University of Kansas, Lawrence, Kansas; UALVP, University of Alberta Laboratory for Vertebrate Paleontology, University of Alberta, Edmonton, Alberta, Canada; 'UNC', uncatalogued specimens (as per Bennett 1991), YPM, Peabody Museum of Natural History, Yale University, New Haven.

Figure 1. Photograph of UALVP 24238. Cranial crest and wing phalanges 2-4 of the left wing have been reconstructed with plaster and paint (on the right side of the photograph), as well as metatarsals of the left foot.

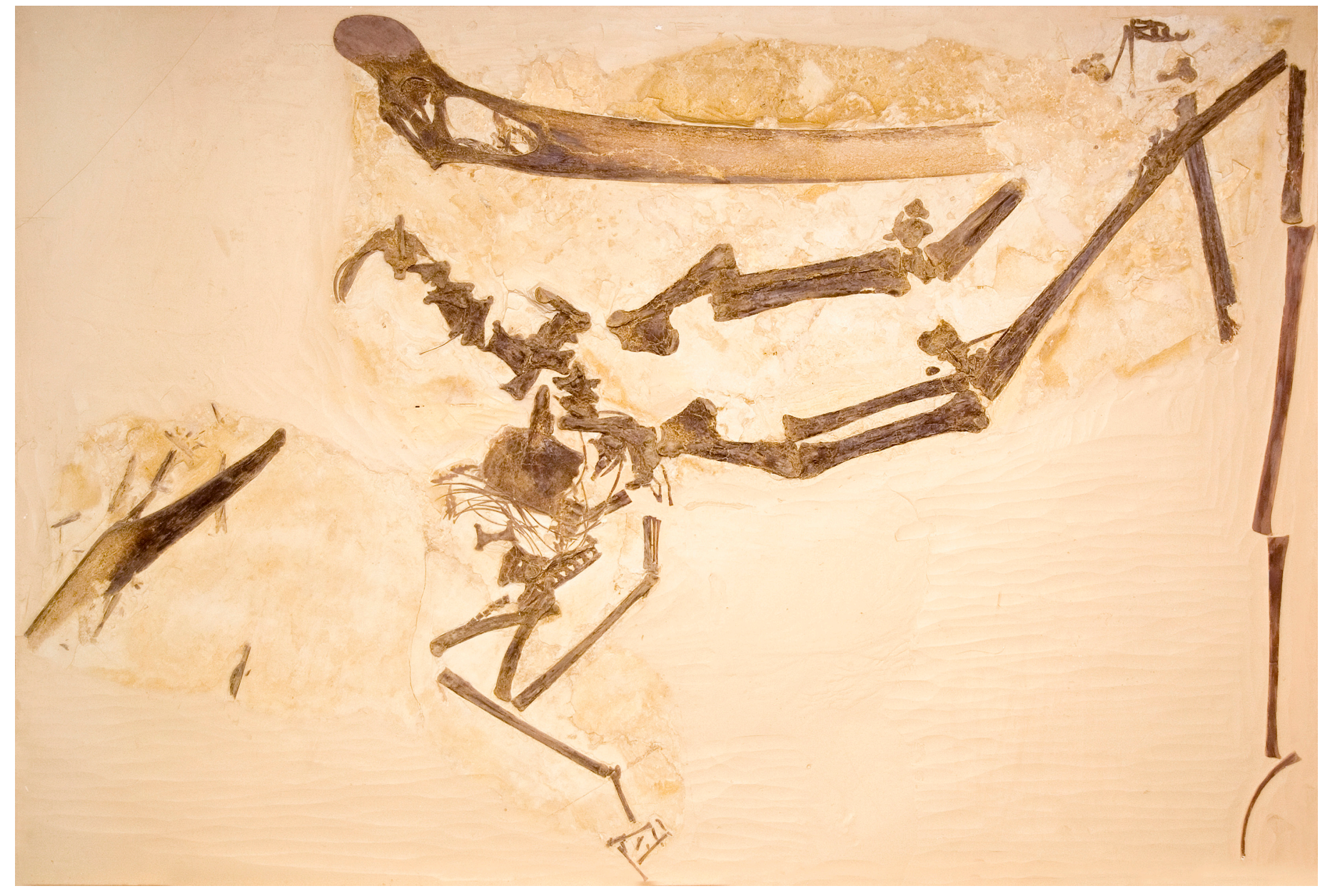




\section{METHODS}

With the protective Plexiglas covering removed from the specimen, osteological features were measured using either Samona Digital Calipers, or a metric tape measure and a string. The occiput-palate angle measurement followed Bennett (2001). The specimen was extensively photographed, and these photos were used in preparation of drawings.

As well, an Ultrafire WF-501B ultraviolet (UV) flashlight was used to visually assess fluorescence and to photographically assess UV reflectance. Photographs were produced using an unmodified Nikon D70 camera fitted with a Nikkor $60 \mathrm{~mm}$ f/2.8 micro-Nikkor lens and a Tiffen 18a filter. Measurements (in pixels, uncalibrated) of the rostral taper of UALVP 24238 and comparable specimens were made using Image (Abramhoff et al. 2004), using our own photographs where possible, as well as published photographs and illustrations (Fig. 3).

\section{SYSTEMATIC PALAEONTOLOGY}

PTEROSAURIA Kaup, 1834

PTERODACTYLOIDEA Plieninger, 1901

EUPTERODACTYLOIDEA Bennett, 1994

ORNITHOCHEIROIDEA Seeley, 1870, sensu Unwin, 2003

PTERANODONTIDAE Marsh, 1876

Pteranodon Marsh 1876

Pteranodon sternbergi Harksen, 1966

Holotype: FHSM VP 339, incomplete skull.

Referred material: as per Bennett (1994): CMNFV

Figure 2. Outline diagram of UALVP 24238. Abbreviations: aa, atlas-axis complex; ac, acetabulum; ax, possible apex of the rostrum; cv, cervical vertebra; cd; caudal vertebra; dc, deltopectoral crest; dc, distal syncarpal; dp, deltopectoral crest; ds, dorsal vertebra; dt, distal tarsal; ep, extensor tendon process; f, femur; gf, glenoid fossa; gs, gastralia; h, humerus; Icd, lateral condyle; If, lower temporal fenestra; Ip, lacrimal process; Ir, left mandibular ramus; It, lateral tarsal; m, mandible; ma, maxilla; mc, metacarpal; mcd, medial condyle; md, manual digit; mt, metatarsal; na, nasoantorbital fenestra; no, notarium; o, orbit; ob, obturator foramen; pc, proximal syncarpal; pd, pedal digit; pr, prepubis; pt, pteroid; px, preaxial carpal; r, radius; ri, rib; rp, retroarticular process; sa, synsacrum, sc, scapulocoracoid; se, sesamoid; sr, sternal rib; st, sternum; t, tibiotarsus; u, ulna; va, ventral mandibular angle; wp, wing phalanx. Circular black dots on the pc and px represent the position of pneumatic foramina. Grey areas represent portions of the rostrum and mandible that are composed of extremely thin trabecular bone.
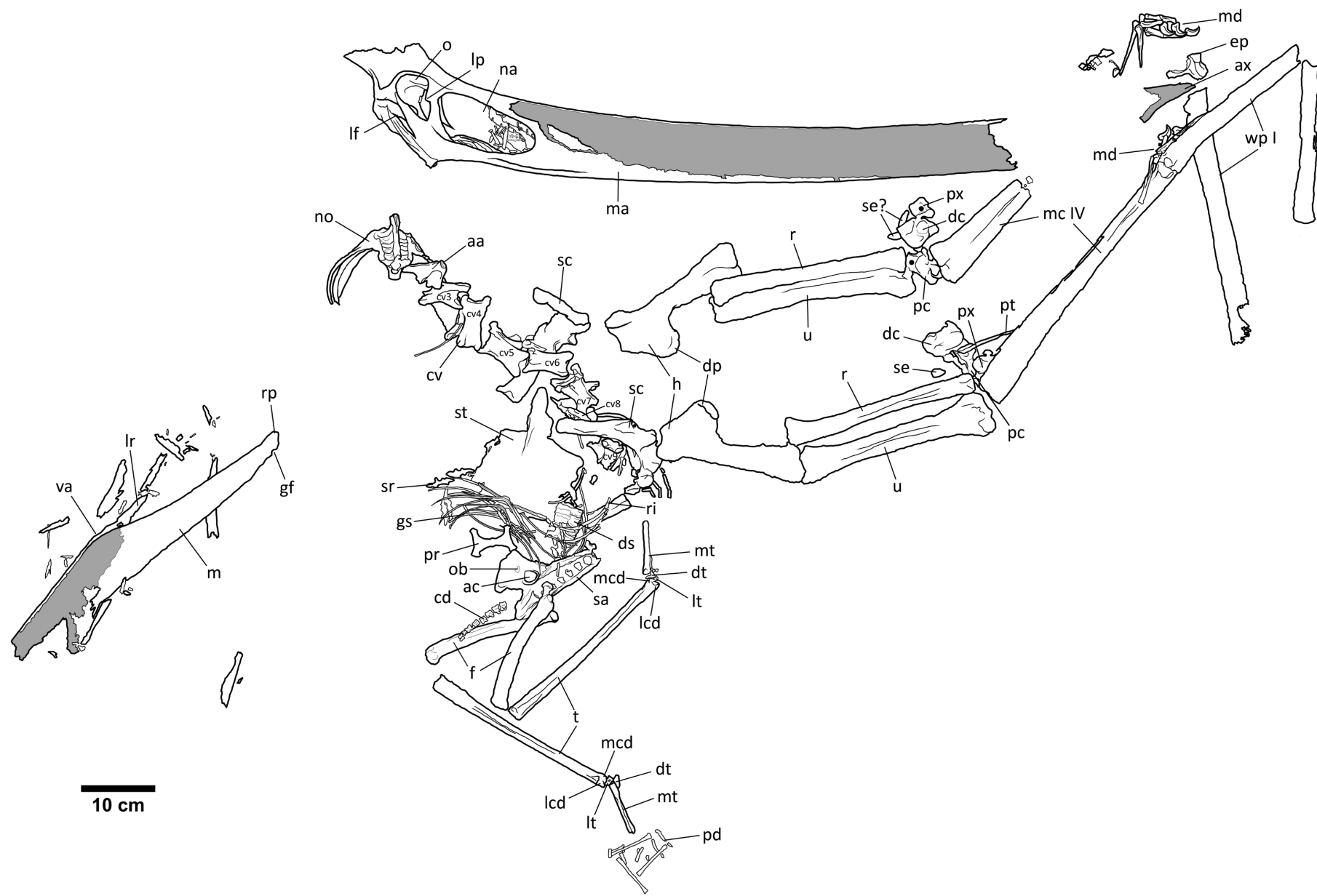


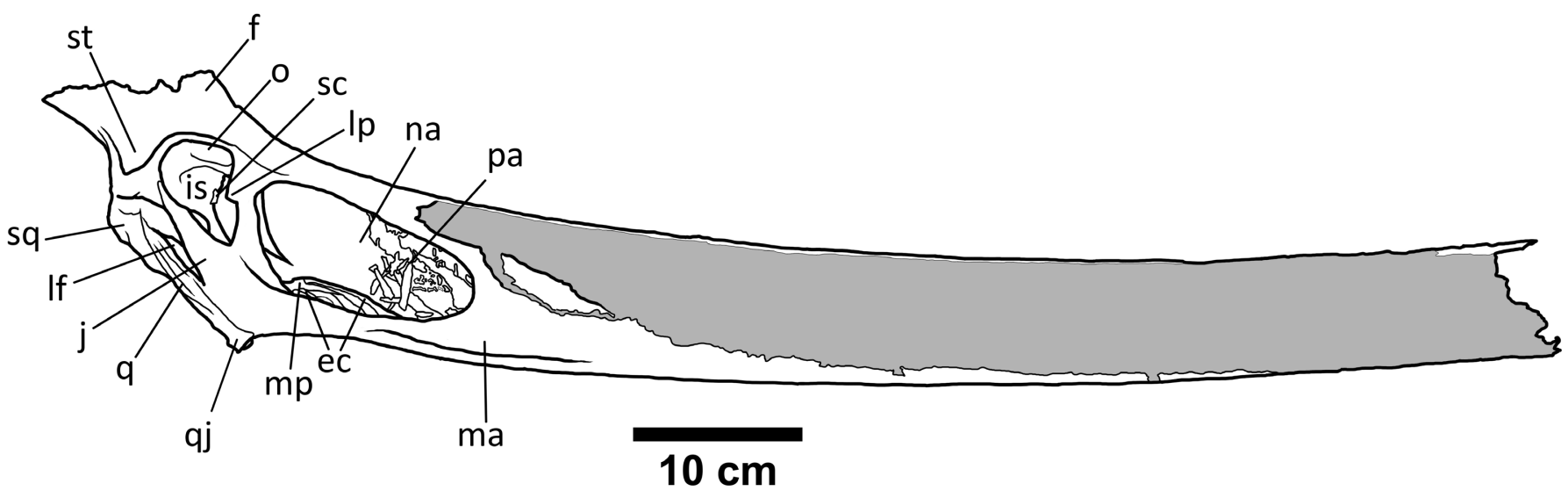

Figure 3. Outline diagram of the skull of UALVP 24238, not including impression of apical fragment. Gray shading indicates exposed endosteal strutting. Abbreviations: ec, ectopterygoids; f, frontal; is, interorbital septum; j, jugal; Ip, lacrimal process; If, lower temporal fenestra; ma, maxilla; mp, median processes of pterygoids; na, nasoantorbital fenestra; o, orbit; pa, palatine; q, quadrate; qj, quadratojugal; sc, segment of sclerotic

41358, ROM 26104, UALVP 24238, 'UNC 3', USNM 12167, 50036, YPM 1181, 2493.

Locality and age: UALVP 24238 was found in 1974, approximately $11 \mathrm{~km}$ north and $1 \mathrm{~km}$ east of Utica, Kansas, USA, in the badlands of Big Windy Creek. It was collected by R. C. Fox, L. A. Lindoe, and B. G. Naylor, for education and display, and has been on exhibit in the Paleontology Museum (formerly Geology Museum) of the University of Alberta, Edmonton, Alberta, Canada, since being prepared shortly thereafter. The precise location of the quarry was not recorded, as was typical for specimens collected in the Smoky Hill Chalk Member by workers at the time (Bennett 1994). In general, the rocks from the quarry area are no higher than Marker Unit 7 of the Smoky Hill Chalk Member, which is early Santonian in age (Hattin 1982). Bennett (1994) places it between marker units 6 and 7.

\section{DESCRIPTION}

UALVP 24238 is a well-preserved, beautifully prepared, and nearly complete skeleton (Figs. 1,2). It is missing only portions of the cranial crest, the rostrum, and mandible, the distal phalanges of both wings, and some bones in the feet. Some elements are fractured, such that fragments of the right mandibular ramus are scattered in the matrix, and the left first wing phalanx is broken near the midpoint. The remaining bones are intact, although somewhat taphonomically compressed. The skeleton is only moderately disarticulated, with both wings swept to the right side of the panel, and there is no doubt that UALVP 24238 is indeed the remains of a single individual. This is remarkable, as majority of Pteranodon specimens are either disarticulated, or are represented by articulated forelimbs alone (Sternberg and Walker 1958; Bennett 1994). A number of features discussed subsequently indicate that this specimen is a not yet osteologically mature subadult. Selected osteological features of the specimen are reviewed in this paper. No helpful patterns of ultraviolet fluorescence or reflectance were detected. This animal had a wingspan of approximately $4 \mathrm{~m}$ based on the lengths of preserved wing bones.

\section{Skull and mandible}

The skull (Fig. 3), visible in right lateral aspect, is large, elongate, low, and laterally compressed, although additional taphonomic compression has also occurred. Sutures between cranial elements are impossible to discern, in part because of post-mortem crushing, and in part because they are typically fused in pterosaur specimens (Eaton 1910). This is particularly true in fully-grown individuals (Bennett 1993). The occiput-palatal angle is approximately $38^{\circ}$.

Memories differ as to why the cranial crest was reconstructed in its current form (Fig. 1), although discussions with both Fox and Lindoe provide valuable insight. They agree that, during excavation, it was determined that no large crest was present (pers. comm. with JHA). This seemed odd at the time, because both workers had in mind the classic image of a large Pteranodon longiceps with a rearward-inclined crest. Fox recalls puzzling over this, and was subsequently interested to learn of the existence of specimens with smaller crests. He then instructed that the crest be reconstructed as small, as a matter of parsimony. Lindoe recalls the presence of a thin darkened layer dorsal to the skull, but it was not recognized at the time as possibly representing the remains of the crest, and so was prepared away. After preparation from the opposite side (the underside), the significance of the darkened layer was realized, and a small crest was reconstructed (as instructed by Fox) using the shape and size of the 
darkened area as a guide.. The preserved anterobasal region of the crest provides a few clues to the shape of the crest in life. It is shortest at the very base (approximately $80 \mathrm{~mm}$ in length), and it expands anteroposteriorly dorsal to its preserved base to the line of breakage. The broken edge of the crest is roughly $104 \mathrm{~mm}$ in length. The premaxillary process forms the anterior portion of the crest, and ends at the same level as the anterior margin of the orbit.

The orbit is roughly piriform, $67.9 \mathrm{~mm}$ high and 27.6 $\mathrm{mm}$ in anteroposterior length. The ventral angle is more acutely pointed than the broadly rounded posterodorsal angle, and the anterodorsal angle is both broadly rounded and obtuse. A brow extends along the dorsal rim of the orbit where the surrounding regions have been slightly crushed, leaving a prominent ridge that has been partly reconstructed in plaster, a feature seen in other Niobrara Chalk pteranodontids. Within the orbit, one segment of the sclerotic ring is present, although it is slightly out of place. The anterior margin of the orbit angles inward at about the midpoint, a feature that Kellner (2010) interpreted as a lacrimal process. This process serves to partially segregate the orbit proper, marking the anteroventral margin of the region occupied by the eyeball and associated sclerotic ring from the space making up the remainder of the piriform orbit typical of many archosaurs.

Anterior to the orbit, the nasoantorbital fenestra is a somewhat triangular ellipse $144.5 \mathrm{~mm}$ in length, taller posteriorly (about $65 \mathrm{~mm}$ ) than anteriorly (about $45 \mathrm{~mm}$ before the more or less linear margins begin curving and converging) with dorsal and ventral margins roughly paralleling the outline of the skull. The margins of the fenestra are smooth, implying that it is undistorted. Ventrally, within the fenestra, the ectopterygoids and median processes of the pterygoids are visible, although they are somewhat distorted. Anteriorly, within the fenestra, fragments of the palatine bone are visible, although no recognizable attributes other than location identify the fragments. Within the posterodorsal region of the fenestra, the posterior margin of the left nasoantorbital fenestra is visible.

The narrow, elongate lower temporal fenestra is $60.2 \mathrm{~mm}$ in height, with a maximum anteroposterior length of approximately $10 \mathrm{~mm}$, and oriented parallel to the posteroventral margin of the skull. It appears to be taphonomically crushed. The supratemporal fenestra is more broadly oval, measures approximately $20 \mathrm{~mm}$ in length, and $10 \mathrm{~mm}$ in width, opens dorsally and is filled with plaster.

The rostrum is deep, with subparallel dorsal and ventral margins along its intact length. At its base, measured at the anterior extent of the nasoantorbital fenestra, it is 93 $\mathrm{mm}$ high, and is still about $70 \mathrm{~mm}$ high at its preserved anterior end, approximately $600 \mathrm{~mm}$ anterior to the fenestra. No suture between premaxilla and maxilla can be discerned, nor is there any indication of a dorsal premaxillary crest distinct from the rostrum proper. The thin surface layer of bone, with the exception of some ventral and basal areas of the rostrum, is lost, exposing extensive endosteal struts (trabeculae) throughout the rostrum, as in other large pterosaurs (de Ricqlés et al. 2000).

The matrix anterior to the broken end of the rostrum preserves an impression of two anteriorly converging structures separated posteriorly by matrix (Fig. 4). This probably represents the rostral apex, but the possibility remains that it simply represents the intersection of two separate rostral fragments. Some thin lines of bone overlaying the impression bear a detailed resemblance to the endosteal struts in the better-preserved portion of the rostrum.

The well-preserved interorbital septum is visible within the orbit. The quadrate is slightly crushed, but can be clearly delineated. The condyloid process does not clearly show helical contacts (the "spiral groove and thread" of Eaton 1910), but this area has been largely reconstructed in plaster.

Only the basal portion of the mandible, from the retroarticular process to a point approximately $200 \mathrm{~mm}$ anterior to the ventral mandibular angle, is preserved. It is exposed in right lateral aspect. However, it is distorted so that a short $(120 \mathrm{~mm})$ portion of the left mandibular ramus, and the branching point at the posterior end of the mandibular symphysis are also visible in medial view. Approximately 25 unidentifiable bone shards, presumably from the mandible, are preserved in the surrounding matrix. The mandible is 13 $\mathrm{mm}$ deep at the glenoid fossa (minimum dimension from the ventral margin of the mandible to the lowest point in the concavity of the fossa). It is $73 \mathrm{~mm}$ deep at the ventral mandibular angle, with a length of $265 \mathrm{~mm}$ from the apex of the retroarticular process to the angle. The ventral man-

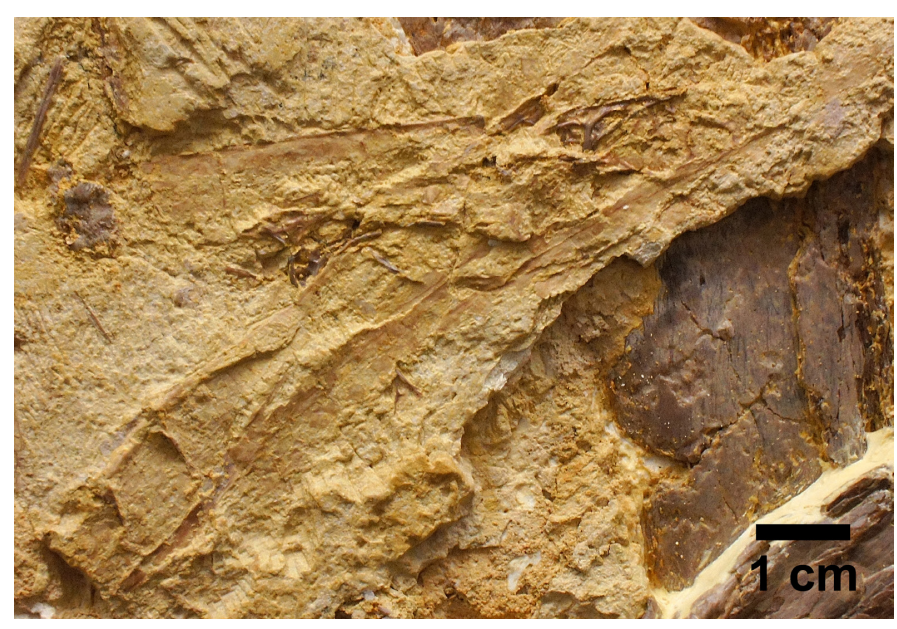

Figure 4. Impression of the possible premaxillary apex of the skull/rostrum, photographed with the protective Plexiglas removed. 
dibular angle (gonydial angle) subtends approximately $150^{\circ}$ The elements of the mandible are well fused and impossible to delineate. Endosteal struts are clearly visible in the area of, and anterior to, the ventral angle.

\section{Axial skeleton}

All nine cervical vertebrae are present (Fig. 5). The fused atlas-axis complex (cervicals 1 and 2) is somewhat crushed, about as high as long, and exposed in right lateral aspect. The hemispherical cotyle is concave and higher than wide. It contains a small elongate bone that appears to be a displaced fragment of the articular face. The neural canal is subtriangular anteriorly, and is approximately one third of the diameter of the cotyle. The axis centrum is poorly differentiated from the other elements of the atlas-axis. It has two small ventrolateral pneumatic foramina, a feature commonly found in Pteranodon (Eaton 1910) and other pteranodontoid pterosaurs (Wang et al. 2014a). The spine of the axis is prominent, triangular, directed posterodorsally at about a $30^{\circ}$ angle along its leading edge, and about $40^{\circ}$ along the trailing edge (a line from the base to apex). It accounts for about half of the height of the complex. The right postzygapophysis extends posterolaterally, has a ventrally directed articular face, and a triangular postexapophysis. It extends posteroventrally for a distance approximately equal to the maximum dimension of the cotyle. This element is a more complete and complex structure than those figured by Bennett (2001a).

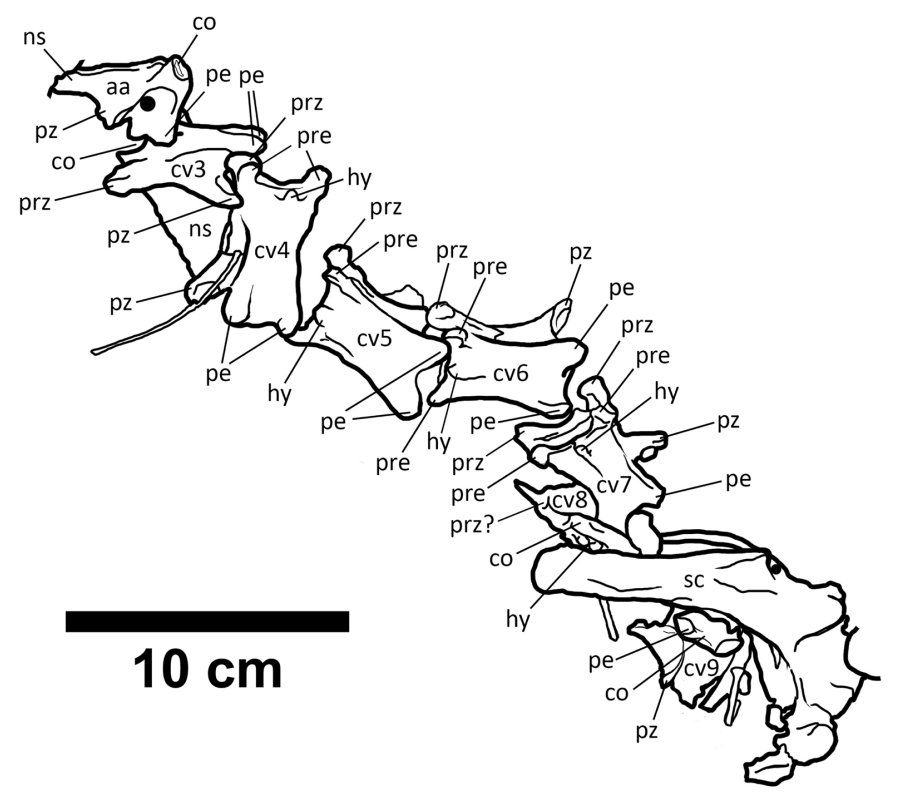

Figure 5. Cervical vertebrae of UALVP 24238.

Abbreviations: aa, atlas-axis complex; co, cotyle; cv, cervical vertebra; hy, hypapophysis; ns, neural spine; pe, postexapophysis; pre, preecapophysis; prz, prezygapophysis; pz, postzygapophysis; sc, scapulocoracoid. Circular black dots on the aa and sc represent the position of pneumatic foramina.
Cervicals 3-6 are elongate, and each of their centra is almost twice the length of the composite centrum of the axis-atlas complex. Cervical 3 (55 $\mathrm{mm}$ in length) is exposed in right lateral aspect, with the centrum somewhat crushed. Its neural spine height equals or exceeds that of the centrum (although the apex is obscured by cervical 4). The leading edge of the neural spine is inclined posterodorsally at about a $50^{\circ}$ angle, and the trailing edge is closer to $80^{\circ}$ (although estimated from a curve). The partially visible anterior cotyle is apparently horizontally oval. The rounded right prezygapophysis is directed anteriorly, although the articular face is covered in plaster. The postzygapophysis is directed posteriorly, and is somewhat more pointed but otherwise similar to the prezygapophysis. Its cracked articular face is directed ventrolaterally. The right postexapophysis is only slightly smaller than the postzygapophysis. Its articular face is not visible. The medial surface of the left postexapophysis is visible but is extensively cracked.

Cervical 4, exposed ventrally, is approximately the same size as cervical 3. The rounded, mid-sagittal hypapophysis is at the anterior end of the centrum. Anterior to the hypapophysis, there is a transverse, shallow depression extending between the two preexapophyses. The vertebra has been crushed so that the right side is also visible. The postzygapophysis is clearly larger and more prominent than the postexapophysis. The right prezygapophysis is more extensively exposed than the left. A thin, partial rib overlies the right posterior portion of this vertebra, obscuring the postzygapophysis.

Cervical 5 is also exposed ventrally, although part of the left side is crushed into the same plane. The hypapophysis is slightly smaller than that of cervical 4 but is of the same general shape. Cervicals 6 and 7 are exposed ventrally and share a subrectangular form with that of cervical 5 . Foramina are visible on the ventral and lateral sides of several of these cervical vertebrae, likely representing pneumatic and nutrient foramina. Cervical 8 is exposed in anterior aspect, but it is partly obscured by cervical 7 and the left scapulocoracoid. The transversely elongate-oval cotyle, and prezygapophyses of cervical 8 are clearly visible, and are similar to those of cervical 7 (allowing for taphonomic distortion). However, the hypapophysis is wider, and apparently divided into two by a medial, longitudinal groove. Bennett (2001a) convincingly interprets the two prominences as muscle scars. Cervical 8 is laterally expanded, due to fusion with the cervical ribs (Bennett 2001a). Cervical 9 is exposed in posterior aspect, but is also partially obscured by the left scapulocoracoid. The condyle, postexapophyses, postzygapophyses, and the transverse processes of cervical 9 are clearly visible. A portion of the neural spine has been reconstructed in plaster. 
The notarium, including five vertebrae and three or four associated ribs (these ribs are more visible on the right side), is exposed in posterodorsal aspect above and to the left of the atlas-axis complex. The first right notarial rib is much broader than those posterior to it.

The right sides of four free dorsal vertebrae are visible below and to the right of the sternum. The ribs have been separated from their respective transverse processes. They are much smaller than the cervicals, having centra that are only about $1 \mathrm{~cm}$ in length.

The pelvis and synsacrum, exposed in left lateral aspect, are not distinguishable from the same elements in Pteranodon (Bennett 2001a). The concave and hemispherical acetabulum is $15 \mathrm{~mm}$ in diameter. It has an oblong (roughly $4 X 7 \mathrm{~mm}$ ) obturator foramen about $7 \mathrm{~mm}$ from the rim of the acetabulum. The prepubis is disarticulated from the rest of the pelvis and visible in dorsal aspect. It is H-shaped but rather wide, slightly convex, and slightly expanded at the apices of the anterior and posterior arms. The synsacrum is fully fused (no sutures are visible) and seven dorsal openings can be seen along the length of the supraneural plate.

The second to tenth caudal vertebrae (illustrated by Bennett 2001a) are preserved, with a total length of $82 \mathrm{~mm}$ (Fig. 6). The apex of the tail is not preserved.

The ventral surface of the sternum is exposed, with a prominent anterior keel and a scalloped left margin. The area between the sternum and pelvis is strewn with ribs, sternal ribs, and gastralia (both medial and lateral elements) (Bennett 2001a).

\section{Appendicular skeleton}

The appendicular skeleton (Tab. 1) is mostly intact, but partially disarticulated. The three distal elements of the left wing digit and three of the metatarsals in the left hind limb have been reconstructed in plaster. A few other elements in a small area to the right of the sternum, where a section of the specimen and matrix is missing, have also been reconstructed.

Shoulder girdle and forelimbs: As displayed, the right forelimb lies above the left (Figs. 1, 2). The scapulocoracoids are U-shaped, and robust. The right scapulocoracoid lies beneath the fifth and sixth cervical vertebrae, and is more badly crushed than the left. The articular face of the right coracoid, however, is well preserved and clearly visible. It has a somewhat elongate oval outline. The coracoid is slightly expanded at its apex. The left scapulocoracoid lies in articulation with the humerus, and the articular face is visible and intact. The coracoid arm is broken off, and the distal fragment is partially reconstructed in plaster.

The humeri are large and robust, with large, slightly curved deltopectoral crests ending in elongate terminal expansions. Both are exposed in ventral aspect. The proximal humeral articulation is saddle-shaped, and the distal
Table 1: Appendicular bone lengths in $\mathrm{mm}$.

\begin{tabular}{lcc}
\hline Bone: & $\begin{array}{c}\text { Length: } \\
\text { Left }\end{array}$ & Right \\
& 205 & 205 \\
Humerus & 273 & 273 \\
Ulna & 265 & 265 \\
Radius & 395 & NA \\
Metacarpal IV & $444^{*}$ & NA \\
Digit IV phalanx I & $271 \mathrm{~mm}$ & $267 \mathrm{~mm}$ \\
Tibiotarsus & & \\
\hline
\end{tabular}

* indicates estimate.

end of the humerus is distinctly expanded. Both humeri measure $205 \mathrm{~mm}$ in length. Neither humerus clearly preserves the pneumatic or nutrient foramina characteristic of Pteranodon, presumably because the surfaces on which these foramina are located are also highly fragmented. The ulnae and radii are elongate, robust, and somewhat expanded at both ends. Both ulnae are approximately 273 $\mathrm{mm}$ long. The right radius has been crushed into the right ulna. The left is in articulation with the humerus. The radii are slightly shorter than the ulnae, and about two-thirds their diameter (Tab. 1).

Both the right and left wings preserve the proximal and distal syncarpals, as well as the preaxial carpal. The right proximal syncarpal is preserved in near-distal aspect, such that the dorsal surface is also visible, and a foramen (possible pneumatic) appears to be present on its dorsal side. The right distal syncarpal is preserved in distal aspect, while the preaxial carpal is visible in dorsolateral aspect,

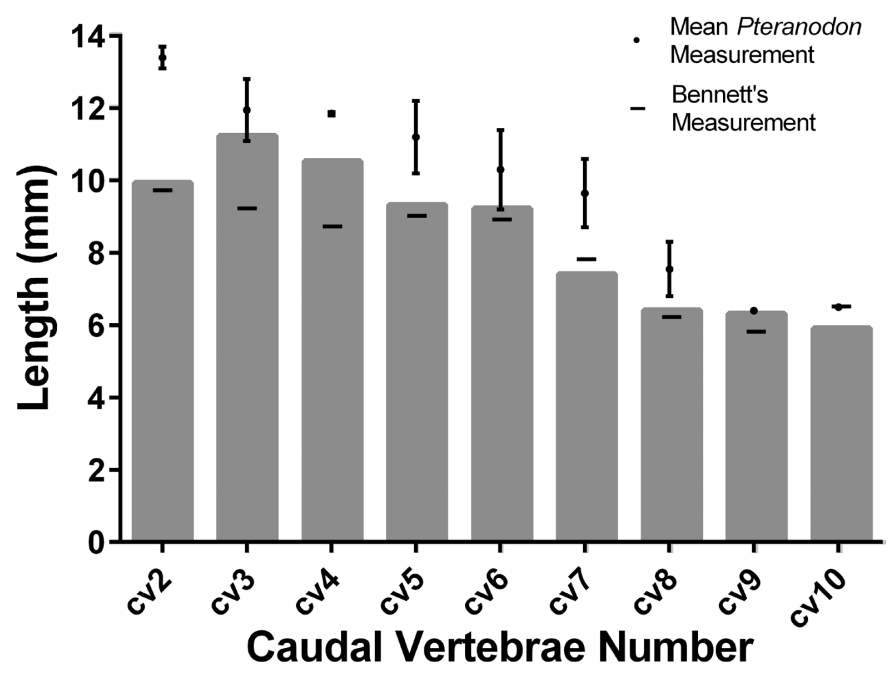

Figure 6: Caudal vertebrae lengths, comparing our measurements (in grey) of UALVP 24238 with those of Benett (2001a), as well as the mean and range of vertebral lengths reported for other Pteranodon sensu lato (Bennett 2001a) based on AMNH 6158, UALVP 24238, YPM 2489, YPM 2462, and YPM 2546. 
with some potential pneumatic foramina preserved. The proximal articulation of the pteroid is also present. The proximal syncarpal lies almost in articulation and life position, while the distal syncarpal and preaxial carpal have been pushed laterally out of articulation. The base of right metacarpal IV is visible, with most of the remainder underlying the rostrum and covered in plaster. A possible foramen lies on the proximal end of the shaft, $23 \mathrm{~mm}$ from the basal articular surface. The bones of the first three digits of the right limb lie at the top of the display panel, separated from the rest of the limb. They include two small, thin metacarpals with tapered, pointed bases. The phalanges of all three digits, including the three rather short but strongly curved unguals, are also present.

The left carpus is more poorly preserved than the right, and has been pushed laterally out of articulation. The proximal syncarpal is present, but crushed, and no features can be determined, while the left distal syncarpal is also preserved in distal view and displays a possible pneumatic foramen. The preaxial carpal is also crushed and poorly preserved. A small sesamoid bone is present. The left pteroid is an elongate, tapering bone with the apex obscured by the base of metacarpal IV, and the base broken off. A fragment of bone to the left of the broken end may be part of the base. The left metacarpal IV is intact along its length, although crushed, and it articulates apically with the jumbled bones of the first three, smaller digits (this area is difficult to interpret, although one ungual is clearly visible), and the fourth, elongated digit of the wing.

The elongate and robust fourth digits of both wings are damaged. The right digit IV is broken off at the distal end of the first wing phalanx (IV-1), and the left is broken in the middle of the shaft of IV-1, with the distal end now orientated at about a $45^{\circ}$ angle from the proximal half. Although an estimate, it is the longest bone, approximately $444 \mathrm{~mm}$ long (Tab. 1). The left IV-1 has a cortical thickness in the shaft of $1.3 \mathrm{~mm}$. Both fourth digits are missing phalanges II-IV, but on the left wing, these elements have been recreated in plaster.

Hind limbs: The left hind limb lies above the right on the panel. Both femora are intact, slightly curved, and show only modest expansion of the ends. The head of the left femur meets the shaft at roughly a $45^{\circ}$ angle (although this area is fractured). Based on a composite impression of the right and left heads, each partially visible, the articular head is hemispherical and smoothly rounded. Both tibiotarsi lie close to their articulated positions with the femora, and possess both medial and lateral condyles. There is no evidence of the (small, reduced) fibula on either tibiotarsus. The right medial and lateral distal tarsals are visible, as well as five metatarsals and eight phalanges, all of which are difficult to identify because they are disarticulated and scattered. The bones of the left foot include the medial and lateral distal tarsals, one metatarsus, and three apparently articulated digits. The latter are partially reconstructed in plaster and partially hidden under the left scapulocoracoid.

\section{DISCUSSION}

\section{Osteological maturity of UALVP 24238}

Kellner (2010) considered UALVP 24238 to be "ontogenetically adult" based on the fusion of several postcranial elements. However, we suggest that the specimen was a subadult, or at least not yet fully osteologically mature, in that the right radius, ulna and fourth metacarpal all show minimal but obvious pitting on their apices, indicating incomplete ossification of the epiphyses (Bennett 1993). Additionally, the process of the extensor tendon is not visible on the left side, suggesting that it had not yet fused, although it is present on the right WP1. Furthermore, only five vertebrae are incorporated into the notarium of UALVP24238, rather than six (Bennett 2001a). Although the cranial crest is incomplete, the portion that is present indicates that it would have been small. A small crest fits with Pteranodon growth predictions, according to which crests were positively allometric in growth as they approached full size (Bennett 1992, 1993; Tomkins et al. 2013). An estimated wingspan of just under $4 \mathrm{~m}$ indicates this was a smaller individual, less than adult size. Fusion of the extensor tendon process on the right side and the fact that all carpals have fused into the proximal and distal syncarpals, also indicate that UALVP 24238 is nearing, but has not yet attained skeletal maturity (Bennett 1993).

\section{UALVP 24238 as Dawndraco kanzai}

Kellner (2010) described UALVP 24238 as the type and only specimen of a new genus and species, Dawndraco kanzai. He diagnosed the species on the basis of eight features: 1) rostrum more elongate than in other pteranodontids; 2) dorsal and ventral rostral margins sub-parallel; 3) posterior maxillary process forming a $45^{\circ}$ angle with respect to the ventral margin of the skull; 4) lacrimal process in the orbit; 5) lower temporal fenestra narrow and ventrally slit-like; 6) mandibular rami lower than in Pteranodon longiceps; 7) articular end of the mandible shorter than in $P$. longiceps; 8) caudal vertebrae longer, and not abruptly decreasing in size distally as they do in P. longiceps. These features are discussed in order.

Characters 1, 2: The length of the rostrum is impossible to judge, because it is broken, and an unknown portion is missing from the specimen. Additionally, the tip of the mandible is missing, making it difficult to estimate the rostrum length based on the mandible. Its shallow taper (or 
sub-parallel rostral margins) is, however, best interpreted as a real morphological feature, which will be discussed in the section that considers UALVP 24238 as P. sternbergi.

Character 3: The angle between the partial, broken posterior premaxillary process and the ventral margin of the skull is a difficult feature to assess. Both sides of the angle must be estimated along curved bone margins, requiring assessment of tangent lines by eye, compounded by taphonomic deformation of the skull. This angle is no easier to measure than the occiput-palate angle, the value of which Bennett $(1994,2001 a)$ is justifiably skeptical. Furthermore, crushing and deformation in this region of the Pteranodon skull is common, seen in the variable shapes of the nasoantorbital fenestra in different skulls, indicating further complications with using this as a feature. However, we find a similar angle $\left(45^{\circ}\right)$ to that mentioned by Kellner (2010). This angle in Pteranodon varies from $25-40^{\circ}$, only slightly less than we observed in UALVP 24238. Given the difficulties in accurately determining this angle, the diagnostic value of this character is therefore questionable.

Character 4: The identification of a lacrimal process in the orbit is made possible by the relatively well preserved condition of this part of the specimen. Many Pteranodon skulls, including the holotype of $P$. sternbergi, either do not preserve this region or exhibit extensive crushing, making it hard to compare UALVP 24238 with other specimens. It is therefore possible that a lacrimal process was present in all Pteranodon.

Character 5: The shape of the lower temporal fenestra is even more difficult to assess with any confidence, because this region of the skull is clearly crushed and distorted in a fashion that reduces its apparent width. Furthermore, comparisons to other skulls with preserved lower temporal fenestrae suggest that as preserved, this opening is not any narrower than the variation seen in other Pteranodon specimens with respect to the length of the fenestra (e.g. FHSM VP 339, KUVP 27821, YPM 2594 in Bennett 2001a).

Characters 6, 7: Kellner's mandibular characters are also unconvincing. The phrase "mandibular rami lower than in Pteranodon" is problematic. A "lower" ramus might mean one that is less dorsoventrally "deep", more dorsoventrally deep, or situated more ventrally on the skull. Under any of these interpretations, there is no reason to conclude that the form of the mandible lies outside the range of variation seen in other specimens of Pteranodon sensu lato (Fig. 7). Mandibular ramus depth and concavity have been mentioned in the literature as possible features to distinguish species, but have been considered not diagnostic enough or require more study (Bennett 1994; Hargrave 2007). Nothing about the mandible of UALVP 24238 suggests that it falls outside the range seen in other Pteranodon. Likewise, the sugges-
A

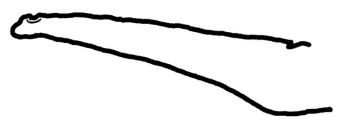

B

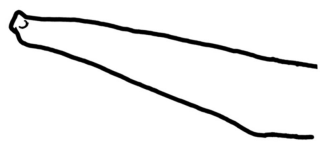

C

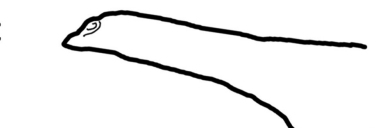

D

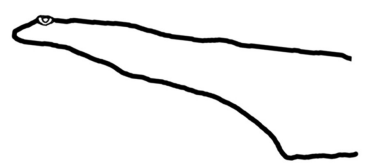

E

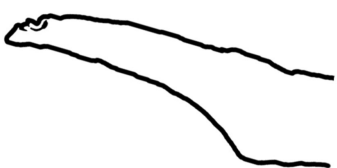

$\mathbf{F}$

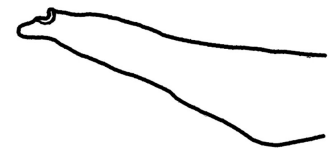

G

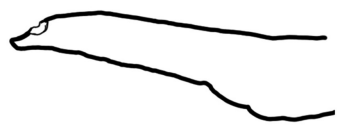

H

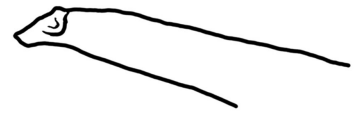

I

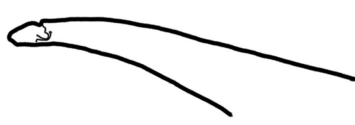

J

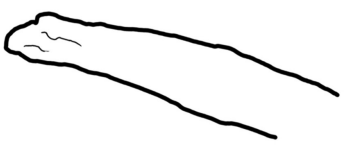

K

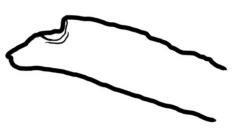

$\mathbf{L}$
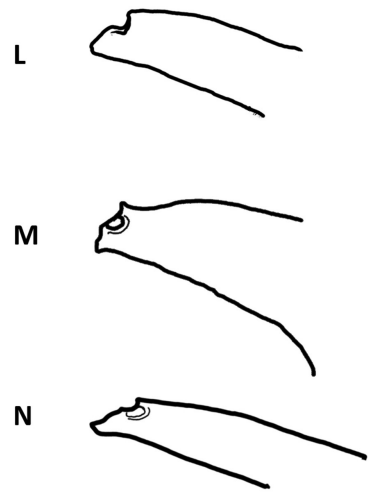

Figure 7. Comparisons of mandibles of Pteranodon sensu lato, in lateral view: A, UALVP 24238; B, KUVP 2212; C, YPM 1117; D, CMC VP 7203; E, FHSM VP 221; F, ANMH 7515, G; USNM 12167; H, FHSM 2183; I, KUVP 27828; J, FHSM VP 2148; K, KUVP 924; L, YPM 2525; M, YPM 1175; N, YPM 2487. A, from original photographs. B, D- H, J, and K after photographs in Everhart (2014). C, after photo in Eaton (1966). I, L, M, and N after illustrations in Bennett (2001). Mandibles not to scale.

tion that the articular end of the mandible is shorter in UALVP 24238 than it is in P. longiceps is puzzling, because the retroarticular process does not appear to be any shorter in UALVP 24238 than in many other specimens of Pteranodon sensu lato (Fig. 7), nor does the posterior portion of the mandible, which may be considered to be the articular end.

Character 8: Kellner states that the caudal vertebrae of UALVP 24238 are longer than those of P. longiceps, but our measurements, and those of Bennett (2001a), show the exact opposite pattern-they are shorter (Fig. 6). Kellner also states that the caudal vertebrae of UALVP 24238 do not abruptly decrease in size distally, as seen in P. longiceps. However, no abrupt distal decrease in size is apparent in measurements of Bennett (2001a) for other Pteranodon, except possibly between caudals 6 and 8 (no measurement for caudal 7 is presented) of YPM 2462, and in AMNH 6158 
between caudals 2 and 3. Clearly, Pteranodon is not diagnosed by caudal vertebrae that markedly decrease in length toward the end of the tail (Bennett, 1994). Overall, the pattern seen in UALVP 24238 mirrors that seen in other Pteranodon, although most measurements for the former are a bit shorter (Fig. 6).

Thus, of the original eight characters used by Kellner (2010) to define the genus and species 'Dawndraco kanzai', most can be accounted for by postmortem distortion, incomplete preservation, or misinterpretation of this specimen. These characteristics do not clearly separate it from Pteranodon. Only the taper of the rostrum seems to merit further consideration.

\section{UALVP 24238 as Pteranodon sensu lato}

Bennett (1994) diagnosed Pteranodon based on 8 cranial and 12 postcranial characters. Four of these characters are visible in UALVP 24238: cranial crest formed from the frontals, directed up or back; edentulous jaws with raised marginal ridges; proximal caudal vertebrae with duplex centra; and distal syncarpal lacking facets for metacarpals I-III. Another defining character is a long and slender beak with the premaxilla and dentary tapering to points (Bennett 1994). The rostrum of UALVP 24238 is incomplete, and the impression of what may be the rostral apex is difficult to interpret. The apex of the mandible is not preserved. No nasal process can be identified, perhaps because the nasal process is reduced. In Pteranodon, the metacarpus is at least 1.5 times longer than the length of the antebrachium (Bennett 1994). On UALVP 24238 the metacarpus is 1.44 times longer than the antebrachium (Table 1), only slightly shorter, and possibly are a result of measurement error and/ or taphonomy. There are no features in UALVP 24238 that distinguish it from Pteranodon.

Miller (1972, 1978) separated Pteranodon sternbergi from $P$. longiceps based on the upright, bulbous crest of $P$. sternbergi, which he considered different enough from that of $P$. longiceps to justify erecting a new genus, 'Geosternbergia,' to accommodate P. sternbergi. However, Bennett (1994) was unconvinced by this argument. Kellner (2010) resurrected the genus Geosternbergia, based primarily on the same characters Bennett (1994) uses to distinguish P. longiceps and P. sternbergi (e.g., upward-directed bulbous crest), as well as features related to the inclination of the premaxillary process and the shape of the lower temporal fenestra. Kellner does not contest that these two species appear to form a clade, as sister species with no intervening taxa, and the division of this small clade into two genera seems unwarranted to us. Thus, we prefer to retain the use of Pteranodon in the broad sense, rather than restricting the genus to one species, Pteranodon longiceps.

Kellner (2010) also argues that the type specimen of Pteranodon sternbergi and UALVP 24238 come from slightly different layers of the lower part of the Smoky Hill Chalk Member (Bennett 1994). However, stratigraphic distributions of Pteranodon, and especially P. longiceps, show persistence of species across multiple strata (Bennett 1994), a pattern also seen in invertebrates, chondrichthyans, osteichythyans, mosasaurs, and birds in the Smoky Hill Chalk Member (Everhart 2005; Carpenter 2008), and in itself does not justify the separation of UALVP from $P$. sternbergi.

\section{UALVP 24238 as Pteranodon sternbergi}

Bennett (1992) identified UALVP 24238 as a male $P$. sternbergi (it falls within his large size class, and is therefore male, and as it comes from the lower part of the Smoky Hill Chalk Member, he identifies it as P. sternbergi). Bennett (1994) diagnoses P. sternbergi on the basis of five structural characteristics not shared with P. longiceps: cranial crest bulbous and upright (perhaps "dorsally directed, laterally compressed, and anteriorly arcuate" would have been a better description than "bulbous," because the latter implies three-dimensional roundness); crest shortest at the base and broader dorsally; premaxillae extending onto the anterior rim of the crest; apparent presence of a median process, formed by the palatines, or vomers within the confluent choanae; and an angle of $36^{0}-41^{\circ}$ between the occiput and the palate (compared to $24^{\circ}-29^{\circ}$ in P. longiceps). UALVP 24238 exhibits only one of these characteristics clearly, in that the angle between the occiput and the palate is roughly $38^{\circ}$. However, Bennett (1994) is hesitant to fully endorse this feature as diagnostic, recognizing that it is an imprecise measurement, performed on taphonomically distorted material. With respect to the remaining three diagnostic characters, the crest itself is mostly absent, and the palatines and vomers are crushed beyond interpretation. Nonetheless, observations of the cranial crest indicate that it does expand dorsally $(80 \mathrm{~mm}$ wide at the base, $104 \mathrm{~mm}$ at the broken dorsal margin), which is inconsistent with $P$. longiceps (Bennett 1994). Although the mandibular features mentioned here are generally not considered to be diagnostic, UALVP 24238 does share general features consistent with $P$. sternbergi, including a mandibular ramus not as deep as in P. longiceps (Bennett 1994), and dorsally concave ventral margin (Hargrave 2007). Bennett (1992, 1994) introduced statistical analyses to the study of Pteranodon, and provided a simple, yet convincing reinterpretation of the typological over-splitting that had hitherto characterized the taxonomy of this genus. Yet Kellner's (2010) discussion of this matter does not include any mention of the bimodal pattern documented by Bennett (1992) for the postcrania of Pteranodon. He attributes Bennett's conclusion that Pteranodon was sexually dimorphic to "two types of pelves", despite Bennett (1992) showing that there were also two sizes of cranial crest, along with two different size 
classes. Males are identified by having larger crests, larger general body sizes, and narrower pelves, whereas females have smaller crests, smaller body sizes, and wider pelves. Kellner also stated that Bennett identifies UALVP 24238 as a female when in fact he considered it a male (a member of the larger size class).

Kellner's (2010) only quantitative comparison is the rostral value, which was previously described as the 'rostral index' by Martill and Naish (2006). He presents values for only two specimens, one of which (UALVP 24238, the specimen considered here) cannot be measured with certainty because the rostrum is incomplete. Rostral value is defined by Kellner as the rostral length, from the anterior edge of the nasoantorbital fenestra to the apex, divided by the height of the rostrum at the most anterior edge of the nasoantorbital fenestra, measured perpendicular to the ventral margin of the rostrum. To Kellner, it is significant that the rostral value is 16.3 in the holotype of Pteranodon longiceps, whereas in UALVP24238 it is more than 20. The use of rostral index used for the holotype of P. longiceps (YPM 1177 ) is questionable due to the likelihood that this specimen does not have a complete rostrum. Complete skulls of Pteranodon (AMNH 7515, CMNFV 41358) show that this animal had a longer upper jaw than lower jaw. This feature is identified by Bennett (1994) as a character diagnosing Pteranodon, suggesting YPM 1177 may be missing the tip of the rostrum.

A more tractable measure than "rostral value" might be a measure of proximal rostral taper. This can be defined as the percent taper in height over an anteroposterior distance four times the basal height. The basal height is measured at the anterior margin of the nasoantorbital fenestra where possible, or at the most basal portion of an incomplete rostrum, because the taper is more or less even, except near the rostral apex (Fig. 8). This taper ratio is an approximate measure of comparison calculated for a variety of rostra, measured from photographs and published illustrations. Despite its lack of precision, the ratio produces an informative pattern (Fig. 9). Two other specimens (CMNFV 41358, KUVP 967) exhibit rostral tapers of the same

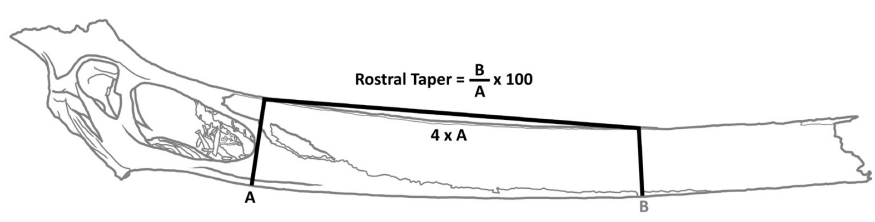

Figure 8. Method for measuring percent rostral taper, calculated as the percent reduction in rostral height from the rostral base (measured at the anterior extent of the nasoantorbital fenestra where possible, or at the most basal preserved portion of incomplete rostra) to a distance four times that of the basal height. magnitude as that of UALVP 24238. It is apparent that the rostral taper of UALVP 24238 is not exceptional, although it is much shallower than those of five of the eight rostra measured. It may well be that the more strongly tapering rostra represent female specimens, while the weakly tapering rostra represent males. Testing this hypothesis would require, at minimum, careful measurement of all available specimens. However, Bennett (1992) does hypothesize that larger individuals (i.e., males) possessed rostra that were longer than the mandibles, and associated the longer rostra with a shallower taper.

The argument could be made that all three of these shallowly tapering specimens represent 'Dawndraco kanzai', but this conclusion would be unwarranted. The type of P. sternbergi, FHSM 339, shows a rostral taper almost as shallow as that of UALVP 24238. However, its rostrum was largely reconstructed by George Sternberg during preparation (although matching the general shape found in the field according to Bennett 1994), and caution should be applied to using this specimen as typical of P. sternbergi with respect to rostral shape.

The identification of a small, upwards-directed crest in addition to the indications of osteological immaturity in UALVP 24238, in addition to the comments on other morphological features made previously, suggest that this specimen is better identified as a smaller (not fully osteologically mature) individual of the larger size-class (male) Pteranodon sternbergi, as originally identified by Bennett (1992, 1994, 2001a), rather than a new genus or species as identified by Kellner (2010).

\section{Additional comments and conclusions}

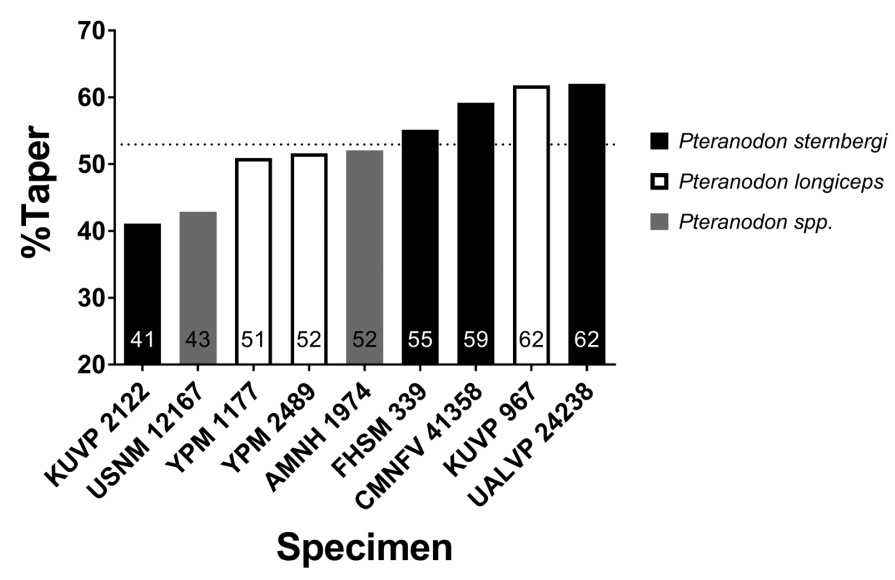

Figure 9. Comparisons of the percent rostral tapers of Pteranodon specimens. Asterisk indicates that basal height was measured from the basalmost portion of the rostral specimen, since the anterior margin of the nasoantorbital fenestra is not preserved. FHSM 339, the type of P. sternbergi, is shown in grey, since the rostrum of this specimen is largely reconstructed. 
It is also worth noting that in assessing the variation in rostrum length, depth, and taper among Pteranodon, Bennett (1992) posits that some specimens possess a low premaxillary crest. On UALVP 24238, he argued that the nearly parallel upper and lower margins of the premaxillae supported a thin, posteriorly decreasing median crest. He assumed the crest was truncated anteriorly. This structure may have been sexually dimorphic, much like the cranial crest. Premaxillary crests are found in a number of pterodactyloid pterosaur taxa (including dsungaripterids, Young 1973; ornithocheiroids, Wang et al. 2014b, Witton 2013; tapejarids, Manzig et al. 2014). These crests are generally recognized by the presence of an extension of the profile of the underlying rostrum, although not necessarily by a difference in bone structure. For species where there is no difference in bone texture (ornithocheiroids), a premaxillary crest can be difficult to identify.

Another interesting feature warranting further discussion is the identification of the rostral apex. Bennett (2001a) does not illustrate any complete rostral apices, only reconstructions. The identification of the rostral apex on UALVP 24238 is based on endosteal struts, and the impressions of the rostral margins. This is unlike any of the elements from a fish, marine reptile, or other animal from the Niobrara Formation. The impression is V-shaped with no contiguous bony connection between the upper and lower arms, and matrix between the arms of the V. This suggests that the dorsal and ventral margins of the rostral apex may have been separated so that the angle does not represent the actual taper in real life, or that these represent fragments of the left and right margins of the rostrum, which have become separated and then crushed. If this is the case, then the rostrum likely would have tapered to a fine point, as seen in CMNFV 41358, an interpretation we consider most likely, rather than this individual showing an uncharacteristically blunt rostral apex.

In conclusion, while it may well be that more than two species are involved in the evolutionary history of Pteranodon, in the absence of additional and better-preserved fossils (and especially complete skulls), Bennett's analysis continues to withstand the test of time as a parsimonious interpretation of the evidence. UALVP 24238 should be considered as a specimen, however odd looking at first glance, of Pteranodon sternbergi.

\section{ACKNOWLEDGEMENTS}

We would like to thank Melissa Baron, Phil Bell, Chris Bennett, Michael Caldwell, Clive Coy, Mike Everhart, Richard Fox, Alicia Glasier, Linda Glasier, Takuya Konishi, Eva Koppelhus, Allan Lindoe, Andrew Locock, Jordan Mallon, Alison Murray, Randy Pakan, Eric Snively, and
Mike Triebold for support, assistance and comments. We also thank D. Hone and M. Witton for helpful comments during review.

\section{LITERATURE CITED}

Abramhoff, M.D., P.J. Magalaes, and S.J. Ram. 2004. Image processing with ImageJ. Biophotonics International 11:36-42.

Bennett, S.C. 1991. Morphology of the Late Cretaceous pterosaur Pteranodon and systematics of the Pterodactyloidea. PhD Thesis. University of Kansas, Lawrence, 400 pp.

Bennett, S.C. 1992. Sexual dimorphism in Pteranodon and other pterosaurs, with comments on cranial crests. Journal of Vertebrate Paleontology 12:422-434. DOI $10.1080 / 02724634.1992 .10011472$

Bennett, S.C. 1993. The ontogeny of Pteranodon and other Pterosaurs. Paleobiology 19:92-106. DOI 10.1017/ S0094837300012331

Bennett, S.C. 1994. Taxonomy and systematics of the Late Cretaceous pterosaur Pteranodon (Pterosauria, Pterodactyloidea). Occasional Papers of the Museum of Natural History, University of Kansas, Lawrence 169:1-70.

Bennett, S.C. 1995. A statistical study of Rhamphorhynchus from the Solnhofen Limestone of Germany: year-classes of a single large species. Journal of Paleontology 69:569-580. DOI $10.1017 /$ S0022336000034946

Bennett, S.C. 1996. Year-classes of pterosaurs from the Solnhofen Limestone of Germany: taxonomic and systematic implications. Journal of Vertebrate Paleontology 16:432-444. DOI 10.1080/02724634.1996.10011332

Bennett, S.C. 2001a. The osteology and functional morphology of the Late Cretaceous pterosaur Pteranodon. Part I. General description of osteology. Palaeontographica Abteilung A 260:1-112.

Bennett, S.C. 2001b. The osteology and functional morphology of the Late Cretaceous pterosaur Pteranodon. Part II. Size and functional morphology. Palaeontographica Abteilung A 260:113-153.

Bennett, S.C. 2003. Morphological evolution of the pectoral girdle of pterosaurs: myology and function. Pp. 191-215 in E. Buffetaut and J.-M. Mazin (eds). Evolution and Palaeobiology of Pterosaurs. Geological Society Special Publications 217.

Bennett, S.C. 2008. Morphological evolution of the wing of pterosaurs: myology and function. Zitteliana B28:127-141.

Bennett, S.C., and P. Penkalski. In press. Waves of bone deposition on the rostrum of the pterosaur Pteranodon. In D.W.E. Hone, M.P. Witton, and D.M. Martill (eds). New Perspectives on Pterosaur Palaeobiology. Geological Society Special Publications 455: doi.org/10.1144/SP455.2.

Carpenter, K. 2008. Vertebrate biostratigraphy of the Smoky Hill Chalk (Niobrara Formation) and the Sharon Springs Member (Pierre Shale). Pp. 421-437 in P.J. Harries (ed.). HighResolution Approaches in Stratigraphic Paleontology. Topics in Geobiology 21. Springer. 
de Ricqlés, A.J., K. Padian, J.R. Horner, and H. FrancillonVeillot. 2000. Paleohistology of pterosaurs (Reptilia: Archosauria): anatomy, ontogeny, and biomechanical implications. Zoological Journal of the Linnean Society 129:349-385.

Eaton, G.F. 1910. Osteology of Pteranodon. Memoirs of the Connecticut Academy of Arts and Sciences 2:1-38.

Everhart, M.J. 2005. Oceans of Kansas: A Natural History of the Western Interior Sea. Bloomington, IN; Indiana University Press, 322 pp.

Everhart, M. 2014. Pteranodons: flying reptiles of the Late Cretaceous western interior sea-a photographic atlas. http:// oceansofkansas.com/pteranodon.html. Accessed Dec. 6, 2016.

Hargrave, J.E. 2007. Pteranodon (Reptilia: Pterosauria): stratigraphic distribution and taphonomy in the lower Pierre Shale Group (Campanian), western South Dakota and eastern Wyoming. Pp. 215-225 in J.E. Martin and D.C. Parris (eds). The Geology and Paleontology of the Late Cretaceous Marine Deposits of the Dakotas. Geological Society of America Special Papers 427.

Harksen, J.C. 1966. Pteranodon sternbergi, a new fossil pterodactyl from the Niobrara Cretaceous Kansas. Proceedings of the South Dakota Academy of Science 45:74-77.

Hattin, D. 1982. Stratigraphy and depositional environment of Smoky Hill Chalk Member, Niobrara (Upper Cretaceous) of the type area. Kansas Geological Survey Bulletin 225:1-108.

Kellner, A.W.A. 2010. Comments on the Pteranodontidae (Pterosauria, Pterodactyloidea) with the description of two new species. Anais da Academia Brasileira de Ciências 82:1063-1084. DOI 10.1590/S0001-37652010000400025

Lü, J., D.M. Unwin, D.C. Deeming, X. Jin, Y. Liu, and Q. Ji. 2011. An egg-adult association, gender, and reproduction in pterosaurs. Science 331:321-324. DOI 10.1126/science. 1197323

Manzig, P.C., A.W.A. Kellner, L.C. Weinschütz, C.E. Fragoso, C.S. Vega, G.B. Guimarães, L.C. Godoy, A. Liccardo, J.H.Z. Ricetti, and C.C. de Moura. 2014. Discovery of a rare pterosaur bone bed in a Cretaceous desert with insights on ontogeny and behavior of flying reptiles. PLOS ONE 9:e100005. DOI 10.1371/journal.pone.0100005
Marsh, O.C. 1871. Note on a new and gigantic species of Pterodactyle. American Journal of Science 3:472.

Marsh, O.C. 1876. Notice of a new sub-order of Pterosauria. American Journal of Science, Series 3, 11:507-509.

Martill, D.M. and Naish, D. 2006. Cranial crest development in the azhdarchoid pterosaur Tupuxuara, with a review of the genus and tapejarid monophyly. Palaeontology 49:925-941. DOI 10.1111/j.1475-4983.2006.00575.x

Miller, H.W. 1972. The taxonomy of the Pteranodon species from Kansas. Transactions of the Kansas Academy of Science 74:1-19.

Miller, H.W. 1978. Geosternbergia, a new name for Sternbergia Miller, 1972; Non Paulo Couto 1970; non Jordan, 1925. Journal of Paleontology 52:194.

Sternberg, G.F. and M.V. Walker. 1958. Observation of articulated limb bones of a recently studied Pteranodon in the Niobrara Cretaceous of Kansas. Transactions of the Kansas Academy of Science 61:81-85.

Unwin, D.M. 2003. On the phylogeny and evolutionary history of pterosaurs. Pp. 139-190 in E. Buffetaut and J.-M. Maxin (eds.). Evolution and Palaeobiology of Pterosaurs. Geological Society Special Publications 217.

Wang, X., T. Rodrigues, S. Jiang, X. Cheng, and A.W.A. Kellner. 2014a. An Early Cretaceous pterosaur with an unusual mandibular crest from China and a potential novel feeding strategy. Scientific Reports 4:6327.

Wang, X., A.W.A. Kellner, S. Jiang, Q. Wang, Y. Ma, Y. Paidoula, X. Cheng, T. Rodrigues, X. Meng, J. Zhang, N. Li, and Z. Zhou. 2014b. Sexually dimorphic tridimensionally preserved pterosaurs and their eggs from China. Current Biology 24:1323-1330. DOI 10.1016/j.cub.2014.04.054

Witton, M.P. 2013. Pterosaurs: Natural History, Evolution, Anatomy. Princeton, NJ: Princeton University Press, 304 pp.

Young, C.C. 1973. Wuerho pterosaurs. Special Publication of the Institute of Vertebrate Paleontology and Paleoanthropology Academia Sinica 11:18-34. 